\title{
Weed Pressure, Yield, and Adhesion of Soil-biodegradable Mulches with Pie Pumpkin (Cucurbita pepo)
}

\author{
Huan Zhang, Lisa Wasko DeVetter, Edward Scheenstra, \\ and Carol Miles \\ Department of Horticulture, Washington State University, Northwestern \\ Washington Research \& Extension Center, Mount Vernon, WA 98273
}

Additional index words. Cucurbita pepo, deterioration, mulch adhesion, plasticulture, polyethylene

\begin{abstract}
A soil-biodegradable mulch (BDM) is designed to be tilled into the soil at the end of the growing season, and is a successful alternative to polyethylene (PE) mulch if it suppresses weeds and improves soil temperature and moisture, crop yield, and fruit quality. This study compared one clear plastic BDM (COX), two black plastic BDMs (BOX and BFO), and two paper BDMs (WGP and AMX) to clear and black plastic PE mulch (CPE and BPE, respectively) for weed control, yield, and mulch adhesion of 'Cinnamon Girl' pie pumpkin (Cucurbita pepo) in a Mediterranean climate where increased soil temperature from mulch is desirable. BDMs in this study are advertised as soil-biodegradable, and we tested functionality but not biodegradability. Mulch deterioration during the growing season was measured as percent soil exposure (PSE), and remained low at the end of the growing season for all BDM and PE treatments both years (5\% on average) except $\mathrm{COX}(68 \%)$. Weed number and biomass were low early, mid, and late season for all treatments except COX in 2018 and COX and CPE in 2019. Soil temperature with $\mathrm{PE}$ mulches $\left(20.7^{\circ} \mathrm{C}\right.$ on average) was similar or slightly higher than with plastic BDMs $\left(19.8^{\circ} \mathrm{C}\right.$ on average $)$, which was higher than with paper BDMs (18.9 ${ }^{\circ} \mathrm{C}$ on average). Total fruit number and yield were similar for $\mathrm{PE}$ mulches (19.3 and $24.5 \mathrm{~kg}$, respectively) and black plastic BDMs (17.3 and $21.2 \mathrm{~kg}$, respectively), which were higher than COX and paper BDMs (15.7 and $19.8 \mathrm{~kg}$, respectively). Mulch adhesion occurred on fruit in all BDM treatments, with more mulch adhesion in BFO in 2018 and WGP in 2019 than in other BDM treatments each year. The number of wipes is a proxy for the impact on harvest labor and can influence overall on-farm profitability. The number of wipes to remove adhered mulch (1.2 wipes on average) was similar for fruit harvested at four times of day $(0800,1000,1200$, and $1400 \mathrm{HR})$, but more wipes were needed to remove adhered mulch when fruit were stored up to 4 hours postharvest (5.4 wipes). Number of wipes to remove adhered mulch was negatively correlated to the amount of moisture on the fruit surface $\left(R^{2}=0.31\right)$. Overall, these findings demonstrate that all black plastic and paper BDMs remained intact throughout the growing season and controlled weeds as well as black PE mulch, while clear BDM had higher weed pressure because it degraded during the growing season. Pumpkin yield was similar for black plastic BDMs and PE mulches and lower for clear and paper BDMs. However, all BDMs in this study adhered to the fruit surface and their removal became more difficult as the fruit surface dried.
\end{abstract}

\begin{abstract}
Received for publication 16 Mar. 2020. Accepted for publication 17 Apr. 2020.

Published online 20 May 2020.

This work was funded in part by the Northwest Agricultural Research Foundation. This work was also supported by the U.S. Department of Agriculture National Institute of Food and Agriculture Hatch projects 1017286 and 1014919.

We thank Ruth Watts of BASF, James Goettmann of Omnifiltra, and Hugo Meunier of FilmOrganic for donating the soil-biodegradable mulches and providing technical advice. We also appreciate the technical assistance of Ronald Dralle, Yao $\mathrm{Mu}$, Michael Dolieslager, Rebekah Timothy, Yixin Cai, and Caroline Klismith and soil and mulch insights from Markus Flury and Douglas Hayes.

C.M. is the corresponding author. E-mail: milesc@ wsu.edu.

This is an open access article distributed under the CC BY-NC-ND license (https://creativecommons. org/licenses/by-nc-nd/4.0/).
\end{abstract}

PE mulch has been used in agriculture since the 1950 s due to the benefits it provides for weed suppression, soil temperature and moisture modification, and yield increase (Kasirajan and Ngouajio, 2012). In 2016, global use of PE mulch was 3.6 million tonnes and $\approx 106,000$ tonnes in North America, and anticipated annual increase is $3.9 \%$ to $4.5 \%$ between 2017 2022 (MarketandMarkets, 2017). It was estimated in 2012 that 20 million ha of agricultural land was covered with PE mulch in China, and recycling has been limited because most of the mulch is thin $(<8 \mu \mathrm{m})$ and difficult to retrieve (Liu et al., 2014). Elsewhere in the world, the contamination of mulch with soil and plant debris $(50 \%$ or more by weight) prevents it from being recycled (Kasirajan and Ngouajio, 2012). Thus, the recycling rate of agricultural PE mulch is low, less than $10 \%$ in the United
States and elsewhere (Briassoulis, 2006; G. Jones, personal communication), and the majority of agricultural mulch is landfilled, stockpiled, or even burned (Goldberger et al., 2015; Kasirajan and Ngouajio, 2012).

The use of BDM is increasing among vegetable growers in recent years because it can provide comparable benefits as $\mathrm{PE}$ mulch and can be disposed in place by tillage into the field (Cowan et al., 2014; Kasirajan and Ngouajio, 2012; Miles et al., 2012). It is important to note, however, that at this time in the United States, BDMs are advertised as biodegradable when tilled into the soil, but BDMs are not required to be tested for soilbiodegradability. In 2018, the European Union released a new standard to test plastic biodegradability in soil [European Norms (EN) 17033, 2018], and this standard is summarized by Hayes and Flury (2018). Most field studies use the term BDM to refer to products that are advertised as biodegradable, but most of these studies test functionality of the BDM during the cropping season and do not test biodegradation of the mulch either during the season or after soil incorporation.

Northwest Washington has a warm Mediterranean climate (Csb) (Peel et al., 2007), with average daily temperature of $15^{\circ} \mathrm{C}$ June through August [Washington State University (WSU) AgWeatherNet, 2019], which influences soil temperature and relative humidity (RH). Black plastic BDM functions similarly to PE mulch as they both increase soil temperature, suppress weeds, and enhance yield (DeVetter et al., 2017; Ghimire et al., 2018; Zhang et al., 2019). Clear plastic mulch can be especially beneficial for production of warm season crops in regions with a Mediterranean climate, due to the increased soil temperature early in the season during a critical period for plant establishment and growth (Waterer, 2000). For example, Dabirian et al. (2017) reported that soil temperature under clear PE mulch was $5{ }^{\circ} \mathrm{C}$ higher than under black PE mulch from early June to mid-August in a watermelon (Citrullus lana$t u s$ ) field in northwest Washington. Al-Assir et al. (1992) also reported that soil temperature under clear PE mulch was 1 to $2{ }^{\circ} \mathrm{C}$ higher than under black $\mathrm{PE}$ mulch in an unheated greenhouse located in Beirut, Lebanon.

Although clear plastic mulch can be beneficial in a region with a warm growing season, weed management can be a problem under clear plastic mulch as light transmission that warms the soil also allows weed development (Lamont, 2005; Waterer, 2000). Past studies have reported that clear plastic $\mathrm{BDM}$ tends to split during the growing season due in part to the heavy weed growth under the mulch, causing weed management concerns (Ghimire et al., 2020; Waterer, 2010). Thus, gains in crop development early in the season may be offset by competition due to increased weed growth under the mulch and when the mulch splits. There are few published studies exploring the use of clear plastic BDM in a Mediterranean climate, 
and it would be valuable to assess the potential relationships of soil temperature, weed growth, BDM splitting, and crop yield.

In contrast to plastic mulch, brown paper mulch reduced soil temperature by $1{ }^{\circ} \mathrm{C}$ in the open field and $1.6{ }^{\circ} \mathrm{C}$ in the high tunnel compared with black PE mulch in tomato production (Solanum lycopersicum) in a Mediterranean climate, but weed control and yield were similar to plants grown with black plastic BDM and PE mulch (Cowan et al., 2014). Ghimire et al. (2018) found that yield of pumpkin (Cucurbita pepo) grown with brown paper mulch was lower than $\mathrm{PE}$ mulch and several black plastic BDMs, but similar to one black plastic BDM and higher than bare ground in a Mediterranean climate. Miles et al. (2012) and Ghimire et al. (2018) also found reduced soil temperature under a brown paper mulch in Knoxville, TN, where the climate is subtropical. Similarly, Anderson et al. (1996) showed that a black paper mulch provided sufficient weed control and similar tomato yield as black PE mulch in Maine that has a humid continental climate. These different results could be due to mulch color, optimal soil temperature for crop growth, or other climatic conditions. Thus, it is worth studying whether a black paper $\mathrm{BDM}$ can provide similar yield as PE mulch in a Mediterranean climate.

BDMs are designed to degrade when exposed to biotic and abiotic conditions in the field (Brodhagen et al., 2015), and deterioration can occur during the growing season, especially where heavy fruit are in contact with the mulch, in some cases resulting in pieces of the BDM adhering to the fruit. For example, Limpus et al. (2019) reported that plastic BDMs adhered to melon (Cucumis melo) and pepper (Capsicum annuum) fruit but was easy to remove. In contrast, Ghimire et al. (2018) found that black plastic BDM and brown paper BDM pieces adhered to pumpkin fruit grown on a silt loam soil with drip irrigation, and adhered mulch was not easy to remove when fruit were wiped with a cloth several hours after harvest. Similarly, it has been reported that plastic BDM adhered to watermelon fruit and was difficult to remove after harvest in the Columbia Basin region of Washington State, which has a continental climate with sandy soil and low humidity conditions and where drip irrigation is used for crop production ( $\mathrm{R}$. Boydston, personal communication, 2009). It is important to note that PE mulch does not adhere to fruit.

The overarching goal of this study was to develop knowledge and practices regarding the use of black paper and plastic BDMs and clear plastic BDM compared with PE mulches for pumpkin production in a Mediterranean climate. The effect of time of day of harvest as well as time after harvest on removal of adhered mulch were also assessed. The specific objectives were to assess different $\mathrm{PE}$ and BDMs for 1) weed incidence, 2) soil temperature and moisture, 3) above-soil deterioration, 4) pumpkin yield, and 5) mulch adhesion on pumpkin fruit.

\section{Materials and Methods}

Experimental location. This study was carried out at the Washington State University Northwestern Washington Research and Extension Center in Mount Vernon, WA (lat. $48^{\circ} 43^{\prime} 24^{\prime \prime} \mathrm{N}$, long. $122^{\circ} 39^{\prime} 09^{\prime \prime} \mathrm{W}$, elevation $6 \mathrm{~m}$ ). The region has a Mediterranean climate with a warm summer, and the 10-year average daily temperature for the growing season (June-August) is $15{ }^{\circ} \mathrm{C}$, with $10{ }^{\circ} \mathrm{C}$ average minimum and $20^{\circ} \mathrm{C}$ average maximum temperature (WSU AgWeatherNet, 2019). During the growing season, the average $\mathrm{RH}$ is $80 \%$, while total precipitation is $39 \mathrm{~mm}$ per month. The soil is Skagit silt loam, a fine-silty mixed nonacid mesic Typic Fluvaquents, with $6.5 \mathrm{pH}, 2.7 \%$ organic matter, and is drained with tile (USDA, 2019).

Experimental design. The experiment was a randomized complete block design with seven mulch treatments (Table 1) and four replications; however, Black Organix (BOX) BDM was only included in 2019 due to late arrival of this mulch product in 2018. Raised beds, 15 to $20 \mathrm{~cm}$ high and $80 \mathrm{~cm}$ wide, were formed and mulch was laid by machine (Model 2600 Bed Shaper; Rain-Flo Irrigation, East Pearl, PA) in all plots. Pie pumpkin cv. Cinnamon Girl (Johnny's Selected Seed, Winslow, ME) was selected for this study as it has a short-vine habit that can maximize potential fruit-to-mulch contact (Ghimire et al., 2018). Each plot was $6 \mathrm{~m}$ long in 2018 and $9 \mathrm{~m}$ long in 2019; plots were longer in 2019 to provide more fruit to test how moisture content on the fruit surface impacts mulch removal. Both years, beds were spaced $2.7 \mathrm{~m}$ center-to-center. In-row spacing was $0.9 \mathrm{~m}$ with plants in a single row. There were six plants per plot in 2018 and 10 plants per plot in 2019. In both years, pumpkins were seeded in the greenhouse in 72-cell trays on 7 May and transplanted to the field on 28 May 2018 and 31 May 2019. Both years, alleyways were mechanically cultivated four times and the sides of beds were cultivated two times to control weeds, until vine growth prevented further cultivation, and then weeds were removed by hand. Plants were scouted for insect pests and disease throughout the growing season both years, and no management practices were needed either year.

Fertilizer and irrigation. Fertilizer (16N7P-13K-7S; Wilbur-Ellis Company, Aurora, $\mathrm{CO})$ was applied before planting at the rate of $118 \mathrm{~kg} \cdot \mathrm{ha}^{-1}$ nitrogen in 2018 and 2019, in accordance with recommendations for the region (Oregon State University, 2019). Fertilizer was applied to the center of each row on 22 May 2018 and 15 May 2019 and was covered with soil when the beds were formed. Drip irrigation tape (T-Tape, Model \#508-08340, 0.2-mm, 20-cm dripper spacing, 4.23 L/ $\mathrm{min} / 100 \mathrm{~m}$ flow rate; Rain-Flow Irrigation, San Diego, CA) was laid simultaneous with mulch laying. Irrigation was applied for $2 \mathrm{~h}$ $(508 \mathrm{~L} / 100 \mathrm{~m})$ twice a week for the first 2 weeks after transplanting, then $3 \mathrm{~h}(761 \mathrm{~L} /$ $100 \mathrm{~m}$ ) once a week thereafter until 10 Sept. both years.
Mulch deterioration. Mulch deterioration was rated visually in the center $1 \mathrm{~m}$ of each plot, between plants 3 and 4 in 2018 and plants 5 and 6 in 2019, two times per month (approximately days 1 and 15 of each month) during the crop season. Mulch deterioration was assessed as PSE where $0 \%$ represents completely intact mulch and $100 \%$ represents fully exposed soil (Cowan et al., 2014; Ghimire et al., 2018). Ratings were in $1 \%$ increments until 20\% exposure and in 5\% increments thereafter. After 1 Aug. both years, the PSE measurement included gently lifting any fruit in the data collection area and including the mulch deterioration under the fruit.

Weed number and biomass. Weeds were measured under all mulch treatments three times both years, early, middle, and late during the growing season. Both years, weeds were measured 3 weeks after transplanting (WAT) (22 June 2018 and 20 June 2019), 10 WAT (9 Aug. 2018 and 8 Aug. 2019), and 15 or 16 WAT (14 Sept. 2018 and 26 Sept. 2019). To measure weeds under the mulch, in 2018 the mulch was cut between plants 1 and 2 for the first measurement, plants 4 and 5 for the second measurement, and plants 3 and 4 for the third measurement. In 2019, the mulch was cut between plants 2 and 3 for the first measurement, plants 8 and 9 for the second measurement, and plants 5 and 6 for the third measurement. Both years, the third measurement area was the same as PSE, and was done after the final PSE measurement. The number of weeds was recorded for each plot, then weeds were clipped at the soil surface and dried at $60{ }^{\circ} \mathrm{C}$ for $48 \mathrm{~h}$, and total dry weight was recorded. For measurements 1 and 2 both years, after weeds were measured, the mulch was laid back over the bed, covered with soil along the sides of the bed, and secured with duct tape across the width of the bed to hold it in place.

Soil temperature and moisture. Soil temperature and moisture (volumetric water content) were recorded both years at a depth of $10 \mathrm{~cm}$ adjacent to the PSE measurement area in each plot of replicate 2, and data were recorded at 15-min intervals. In 2018, temperature and moisture sensors (S-TMBM002 and S-SMC-M005 respectively; Onset Computer, Corp., Bourne, MA) and loggers (Hobo H21-002; Onset Computer, Corp.) recorded data from 28 May to 17 Sept; however, the sensors in the Clear Organix (COX) and AMX-01 (AMX) plots malfunctioned the first week and the last 2 weeks of the experiment, respectively. In 2019, sensors (TEROS 11; Meter Environment, Pullman, WA), and loggers (ZL6; Meter Environment) recorded data from 31 May to 2 Oct.

Fruit yield and mulch adhesion. Pumpkin fruit yield was measured at four harvest times, $0800,1000,1200$, and $1400 \mathrm{HR}$ on 17 Sept. 2018 and 2 Oct. 2019, to assess if time of day of harvest affected removal of adhered mulch. At each harvest time both years, all marketable fruit with orange rind color and a diameter $\geq 10 \mathrm{~cm}$ were harvested from one of 
Table 1. Mulch treatments in a pie pumpkin field trial at Mount Vernon, WA, in 2018 and 2019.

\begin{tabular}{|c|c|c|c|}
\hline Mulch treatments (Abbreviation) & Manufacturer & Thickness $(\mu \mathrm{m})$ & Key product ingredient(s) \\
\hline Black AMX-01 (AMX) & Omnifiltra, Beaver Falls, NY & 254.0 & $-\mathrm{z}$ \\
\hline Brown WeedGuardPlus (WGP) & Sunshine Paper, Aurora, CO & 240.0 & Cellulose \\
\hline Black Film Organic (BFO) & FilmOrganic, Laval, Canada & 15.2 & - \\
\hline Clear Organix (COX) & BASF/Organix Ag., Maple Grove, MN & 17.8 & BASF Ecovio (PLA + PBAT) $)^{y}$ \\
\hline Black Organix $(\mathrm{BOX})^{\mathrm{x}}$ & BASF/Organix Ag., Maple, Grove, MN & 15.2 & BASF Ecovio (PLA + PBAT) \\
\hline Black polyethylene (BPE) & Filmtech, Allentown, PA & 25.4 & Polyethylene \\
\hline Clear polyethylene (CPE) & Filmtech, Allentown, PA & 25.4 & Polyethylene \\
\hline
\end{tabular}

${ }^{\mathrm{z}}$ Information not provided by manufacturer.

${ }^{\mathrm{y}} \mathrm{PLA}=$ polylactic acid; PBAT = poly(butylene adipate-co-terephthalate).

${ }^{\mathrm{x}}$ Only included in 2019.

the center four plants in each plot. Fruit were harvested by cutting with loppers to leave a 2- to 5-cm handle. At each harvest time, marketable fruit number and weight were recorded then number and weight of marketable fruit with mulch adhesion $\left(\geq 1 \mathrm{~cm}^{2}\right)$ were recorded (Ghimire et al., 2018). Total fruit number and weight of marketable fruit and of fruit with mulch adhesion were calculated per plot after all harvests were completed. Removal of adhered mulch was evaluated at each harvest time by wiping fruit with a wet cotton towel to remove adhered mulch, using equivalent wiping pressure for all fruit. The number of wipes to remove adhered mulch were recorded for each plot at each harvest time.

To evaluate the effect of postharvest fruit surface drying on removal of adhered mulch and to avoid soil contamination when measuring moisture on the fruit surface, a $10-\mathrm{cm}$ by $10-\mathrm{cm}$ area immediately above the adhered mulch was wiped clean with a wet cotton towel 1 week before harvest for all fruit on four plants per plot. Fruit were gently lifted and wiped, the cleaned area was marked with a permanent marker, and fruit were placed back in their original position. Fruit harvested from the four plants in each plot were placed in a harvest crate $(60 \times 40 \times$ $20 \mathrm{~cm}$ ) separately by plot at $0800 \mathrm{HR}$ and stored in an open-ended high tunnel to protect fruit from potential rainfall. Water content on the surface of one fruit per plot was measured at harvest (time 0:00) and six time points (hour:minute) postharvest: 1:00, 1:30, 2:00, $2: 30,4: 00$, and 24:00. Time points were based on a pretest carried out 2 weeks before harvest. Moisture on the fruit surface was measured using a filter paper (disc 55-mm diameter, No. 1001-055; Whatman, Buckinghamshire, UK). For each fruit, a filter paper was inserted into a $2.5 \mathrm{~cm}$ by $2.0 \mathrm{~cm}$ impermeable polyethylene plastic zip-lock bag (S15165; Uline, Pleasant Prairie, WI), weighed using an electronic analytic balance (AJ100; Mettler Toledo, Columbus, $\mathrm{OH}$ ), and the dry weight was recorded before the harvest. For each time measurement, the filter paper was placed on the clean surface of the fruit, just above the adhered mulch, and pressed (no back and forth wiping) for $5 \mathrm{~s}$ to absorb all free water. The filter paper was placed back into its respective zip-lock bag, which was closed immediately, reweighed with the same balance, and the wet weight was recorded. Moisture was calculated as dry weight sub- tracted from wet weight. At each time point, immediately after collecting the fruit surface moisture sample, mulch adhered to the fruit was wiped off using a wet cotton towel following the same procedures described earlier, and the number of wipes was recorded.

Statistical analysis. All data were analyzed with JMP14.0.0 (SAS Institute, Cary, NC). Data were evaluated for normality and homogeneity of variance before using analysis of variance (ANOVA). Total fruit number and weight, average fruit weight, and moisture on the fruit surface were analyzed using ANOVA. Mean separations were performed with Tukey's honest significant difference with $\alpha=0.05$. PSE, weed number and biomass, fruit number and weight with mulch adhesion, and number of wipes to remove mulch adhesion were analyzed using a Wilcoxon nonparametric test because no transformation met the assumption of ANOVA, and mean separation were performed with a Wilcoxon nonparametric multiple comparison procedure. PSE were analyzed as a completely randomized block design with repeated measures because PSE was measured several times over the growing season. A linear regression was performed between mulch adhesion removal (number of wipes) and moisture on the fruit surface. Because weed number and biomass, total fruit yield, fruit number and weight with mulch adhesion, and number of wipes to remove mulch adhesion differed due to year and/or the interaction of treatment and year, those data were separated for each year. Original means are presented for all data.

\section{Results}

Percent soil exposure. PSE differed due to treatment $(P=0.009)$ but not due to year $(P=$ $0.52)$. There was an interaction between year and treatment $(P<0.0001)$ as PSE in 2018 was greater for BFO and lesser for WGP than in 2019 (Fig. 1). In 2018, although BFO had the greatest PSE on 15 June $(1.5 \%)(P=$ $0.03)$, COX had the greatest PSE on 2 July (15.5\%; $P=0.03)$, and PSE for COX remained greater than for all other treatments throughout the remainder of the study. At the last PSE assessment, on 13 Sept., COX had the greatest PSE $(62.5 \%)$, followed by BFO $(9.5 \%)$, and all other treatments had very low PSE ( $0.8 \%$ on average; $P=0.03$ ). In 2019, PSE of COX increased significantly on 1 July and was $42.5 \%(P=0.03)$. PSE of COX continued to increase as the season progressed and was $67.5 \%$ on 15 Aug. and $73.8 \%$ on 25 Sept. (the last PSE assessment). In contrast, $\mathrm{BPE}$ and $\mathrm{CPE}$ on $15 \mathrm{Aug}$. had the lowest PSE ( $0.35 \%$ on average), and the other mulches ranged from $1.5 \%$ to $6.3 \% \operatorname{PSE}(P=$ $0.02)$. A similar trend remained until the last PSE assessment on 25 Sept., when BPE and CPE had $0.6 \%$ PSE on average, and PSE for $\mathrm{AMX}, \mathrm{BFO}, \mathrm{BOX}$, and WGP ranged from $5.5 \%$ to $14.8 \%(P=0.02)$.

Weed number and biomass. Weed number differed due to treatment $(P<0.0001)$ and year $(P=0.009)$, and there was an interaction between treatment and year $(P=0.0002)$. Weed number was low on all three weed collection dates for all treatments except for COX in $2018(P=0.02)$ and COX and CPE in $2019(P=0.03)$, and weeds in most treatments were too small to be measured for biomass the first and second collection dates both years (Table 2). In 2018 early season (22 June), COX (2.0 weeds $\left./ \mathrm{m}^{2}\right)$ and CPE (2.5 weeds $/ \mathrm{m}^{2}$ ) had a higher weed number than other treatments, which all had 0 weed $/ \mathrm{m}^{2}$ $(P=0.04)$; midseason (9 Aug.), COX had a higher weed number $\left(10.0\right.$ weeds $\left./ \mathrm{m}^{2}\right)$ and biomass $\left(2.9 \mathrm{~g} \cdot \mathrm{m}^{-2}\right)$ than other treatments, which averaged 0 weed $/ \mathrm{m}^{2}(P=0.03$ for both). On the last weed collection date (20 Sept.), COX again had a higher weed number (21.0 weeds $/ \mathrm{m}^{2}$ ) and biomass $\left(17.1 \mathrm{~g} \cdot \mathrm{m}^{-2}\right.$ ) than other treatments, which averaged 0.4 weed $/ \mathrm{m}^{2}$ ( $P=0.03$ for both). In 2019 , weed number early season (20 June) was greatest for BOX (7.0 weeds $\left./ \mathrm{m}^{2}\right)$ and $\operatorname{COX}(6.8$ weeds $\left./ \mathrm{m}^{2}\right)$, lowest for BPE $\left(0.3\right.$ weeds $\left./ \mathrm{m}^{2}\right)$, and intermediate for all other treatments $(2.0$ weeds $/ \mathrm{m}^{2}$ on average) $(P=0.02)$. Midseason, both weed number and biomass were highest for $\operatorname{COX}\left(77.5\right.$ weeds $/ \mathrm{m}^{2}$ and $58.3 \mathrm{~g} \cdot \mathrm{m}^{-2}$, respectively; $P=0.02$ for both), which was statistically similar to number of weeds for CPE (16.5 weeds $\left./ \mathrm{m}^{2}\right)$. At the end of the season (26 Sept.), weed number was highest for COX (89.5 weeds $\left./ \mathrm{m}^{2}\right)$ and CPE (39.0 weeds $/ \mathrm{m}^{2}$ ), intermediate for WGP (4 weeds/ $\mathrm{m}^{2}$ ), and lowest for BPE and BFO (both had no weeds) $(P=0.02)$. Weed biomass was 81.2 and $3.6 \mathrm{~g} \cdot \mathrm{m}^{-2}$ for COX and CPE, respectively. Weeds in this study were primarily chickweed (Stellaria media), lady's thumb (Persicaria maculosa), pigweed (Amaranthus retroflexus), Shepherd's purse (Capsella bursa-pastoris), and annual ryegrass (Lolium multiflorum). 


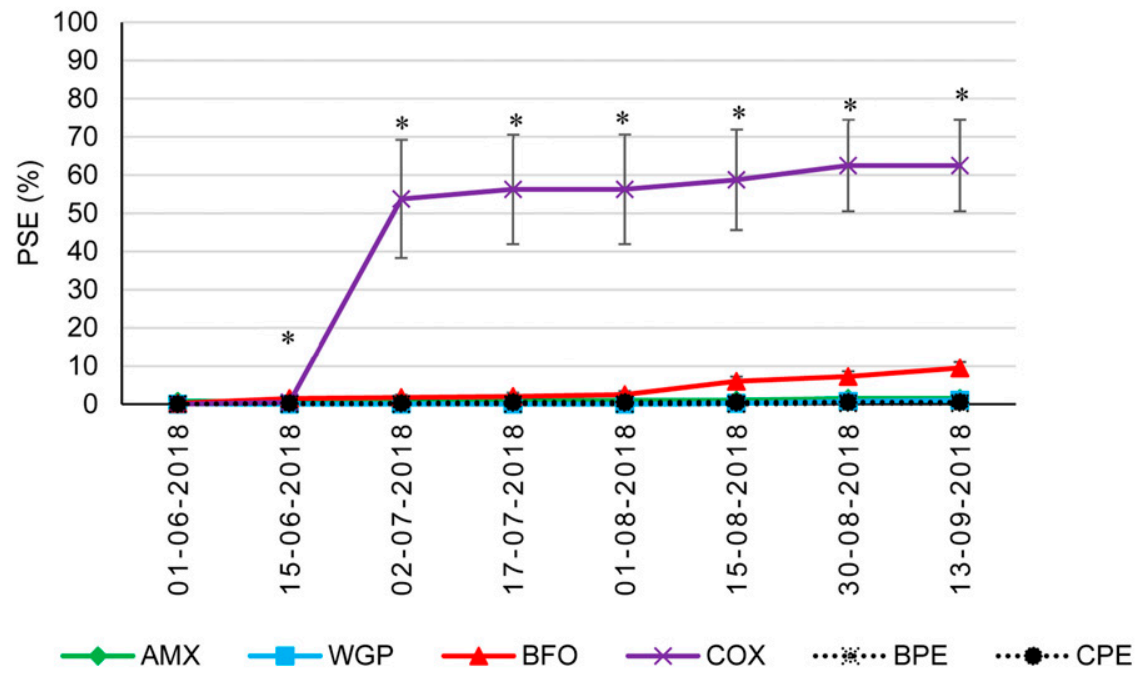

B

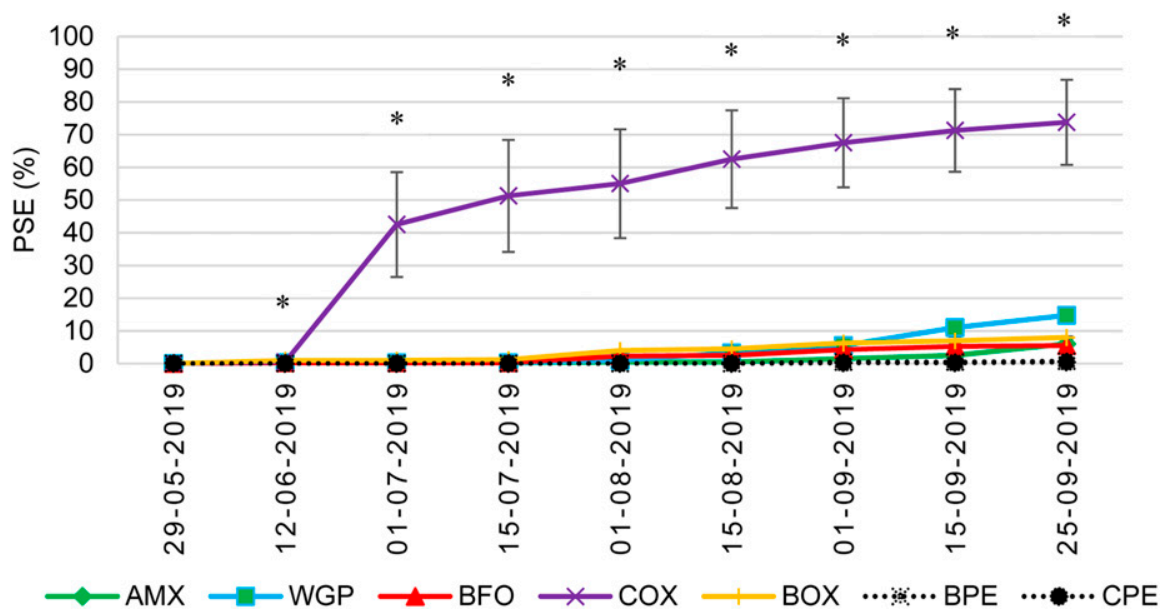

Fig. 1. Percent soil exposure (PSE) for clear and black polyethylene mulch (CPE and BPE) and soilbiodegradable mulch treatments [AMX-01 (AMX), WeedGuardPlus (WGP), Black Film Organic (BFO), Clear Organix (COX), and Black Organix (BOX)] over the pumpkin growing season at Mount Vernon, WA, in 2018 (A) and 2019 (B). Plants were transplanted on 28 May 2018 and 31 May 2019 and harvested on 17 Sept. 2018 and 2 Oct. 2019. *Significant difference at $P<0.05$ using a nonparametric Wilcoxon multiple comparison test. BOX was not included in 2018. The error bar indicates SE.

Soil temperature and moisture. In general, soil temperature and volumetric water content under plastic mulches were greater than with the paper mulches (Fig. 2). The average soil temperature across all treatments was 19.9 and $19.2^{\circ} \mathrm{C}$ in 2018 and 2019 , respectively, and there was a similar trend among treatments both years. In 2018, soil temperature under CPE and COX was 1.6 and $1.2{ }^{\circ} \mathrm{C}$, respectively, higher than the average. $\mathrm{BPE}$ and BFO were similar to the average, and AMX and WGP were 1.1 and $1.8{ }^{\circ} \mathrm{C}$, respectively, lower than the average (Fig. 2A). In 2019, soil temperature under $\mathrm{CPE}$ and $\mathrm{BPE}$ was 2.0 and $0.5{ }^{\circ} \mathrm{C}$ higher, respectively, than the average. $\mathrm{BFO}, \mathrm{COX}$, and BOX were similar to the average, and AMX and WGP were 0.8 and $1.3{ }^{\circ} \mathrm{C}$, respec- were 0.03 and $0.02 \mathrm{~m}^{3} \cdot \mathrm{m}^{-3}$, respectively, lower than the average (Fig. 2D).

Fruit yield. Total fruit number per plot differed due to treatment $(P=0.009)$ but not due to year $(P=0.96)$, and there was no interaction between treatment and year $(P=$ $0.86)$. The average total fruit number per plot for all treatments was 17.6 fruit in both 2018 and 2019. Total fruit number per plot was highest for BPE, CPE, and BOX (19.1 fruit on average), which were statistically similar to $\mathrm{AMX}, \mathrm{BFO}$, and $\mathrm{COX}$ (16.9 fruit on average) and was lowest for WGP (14.9 fruit) $(P=0.003$; Table 3$)$. Total fruit weight per plot differed due to treatment $(P=0.0009)$ and year $(P=0.005)$, but there was no interaction between treatment and year $(P=$ 0.21 ). The overall average total fruit weight per plot for all treatments was 23.1 and 20.0 $\mathrm{kg}$ in 2018 and 2019, respectively (Table 3 ). In 2018, BPE $(27.1 \mathrm{~kg})$ and BFO $(26.3 \mathrm{~kg})$ had the greatest fruit weight per plot, being similar to CPE $(25.2 \mathrm{~kg})$, followed by the other treatments that averaged $20.1 \mathrm{~kg}(P=$ $0.03)$. In 2019 , there was no difference in total fruit weight per plot among treatments $(P=0.07)$, but the trend was similar to 2018 (Table 3$)$. There was no difference in average weight per fruit due to treatment $(P=0.76)$, and there was no interaction between treatment and year $(P=0.77)$, but there was a difference due to year $(P=0.02)$. Average fruit weight was greater in $2018(1.35 \mathrm{~kg})$ than in 2019 (1.20 kg; data not presented).

Fruit yield with mulch adhesion. Number of fruit with mulch adhesion differed due to treatment $(P<0.0001)$ and year $(P=0.04)$, and there was an interaction between treatment and year $(P<0.0001)$. Fruit weight with mulch adhesion also differed due to treatment $(P<0.0001)$; there was no difference due to year $(P=0.17)$, but there was an interaction between treatment and year $(P<0.0001)$. Mulch adhesion occurred in all BDM treatments both years, except AMX in 2018 (Table 3). In 2018, the average number of fruit per plot with mulch adhesion was 4.1 and the average weight was $6.1 \mathrm{~kg}$. BFO had the greatest fruit number $(P=0.02)$ and weight $(P=0.001)$ with mulch adhesion, 8.8 fruit and $13.5 \mathrm{~kg}$ per plot on average, respectively. WGP and COX had similar fruit number (1.5 and 2.0 fruit, respectively) and weight (1.9 and $3.0 \mathrm{~kg}$, respectively) per plot with mulch adhesion. In 2019, on average there were 5.9 fruit per plot with mulch adhesion for all BDM, and average total fruit weight was $7.2 \mathrm{~kg}$. BOX had the greatest fruit number (10.3 fruit) and weight $(11.8 \mathrm{~kg})$ with mulch adhesion per plot, being similar to WGP (7.3 fruit and $9.3 \mathrm{~kg}$ ), whereas BFO had the lowest fruit number and weight with mulch adhesion per plot, 3.0 fruit and 3.7 $\mathrm{kg}(P<0.0001$ for both; Table 3$)$.

Mulch adhesion removal. Removal (number of wipes) of adhered mulch differed due to treatment $(P=0.003)$ and year $(P=0.01)$, and there was an interaction between treatment and year $(P=0.0005)$. Both years there was no difference in mulch adhesion removal due to time of harvest $(P=0.28$ and $P=0.10$, 
Table 2. Weed number per $\mathrm{m}^{2}$ in plots with 'Cinnamon Girl' pie pumpkin grown with polyethylene (CPE and BPE) and soil-biodegradable mulch treatments [AMX-01 (AMX), WeedGuardPlus (WGP), Black Film Organic (BFO), Clear Organix (COX), and Black Organix (BOX)] in 2018 and 2019.

\begin{tabular}{|c|c|c|c|c|c|c|}
\hline \multicolumn{7}{|c|}{ Weed number per $\mathrm{m}^{2}$} \\
\hline Treatment & \multicolumn{3}{|c|}{2018} & \multicolumn{3}{|c|}{2019} \\
\hline$\overline{\mathrm{AMX}}$ & $0 \mathrm{~b}^{\mathrm{y}}$ & $0 \mathrm{~b}$ & $0.5 \mathrm{~b}$ & $2.3 \mathrm{ab}$ & $0 \mathrm{~b}$ & $0.3 \mathrm{bc}$ \\
\hline BFO & $0 \mathrm{~b}$ & $0 \mathrm{~b}$ & $0.8 \mathrm{~b}$ & $1.3 \mathrm{ab}$ & $0 \mathrm{~b}$ & $0 \mathrm{c}$ \\
\hline $\operatorname{cox}$ & $2.0 \mathrm{a}$ & $10.0 \mathrm{~b}$ & $21.0 \mathrm{a}$ & $6.8 \mathrm{a}$ & $77.5 \mathrm{a}$ & $89.5 \mathrm{a}$ \\
\hline $\mathrm{BOX}$ & $-^{x}$ & - & - & $7.0 \mathrm{a}$ & $0 \mathrm{~b}$ & $0.3 b c$ \\
\hline BPE & $0 \mathrm{~b}$ & $0 \mathrm{~b}$ & $0 \mathrm{~b}$ & $0.3 \mathrm{~b}$ & $0 \mathrm{~b}$ & $0 \mathrm{c}$ \\
\hline
\end{tabular}

${ }^{\mathrm{z}}$ Weeds were collected 3 weeks after transplanting (WAT; 22 June 2018 and 20 June 2019), 10 WAT (9 Aug. 2018 and 8 Aug. 2019), 15 WAT (14 Sept.) in 2018, and 16 WAT (26 Sept.) in 2019.

${ }^{\mathrm{y}}$ Means followed by the same letter in the same column are not significantly different at $P<0.05$, using a nonparametric multiple comparisons Wilcoxon test. ${ }^{\mathrm{x}}$ This treatment was not included in 2018 .

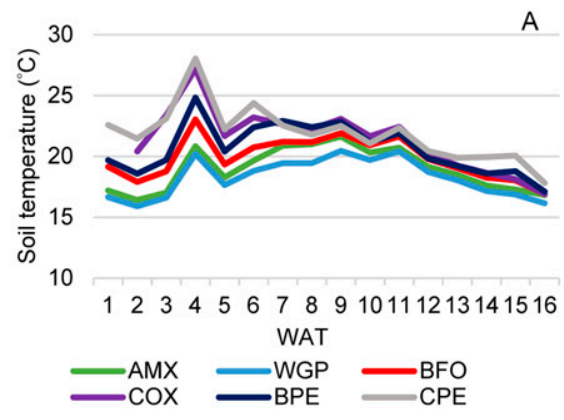

C

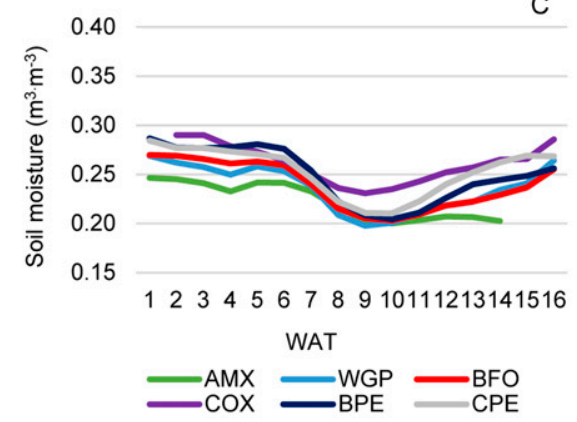

B

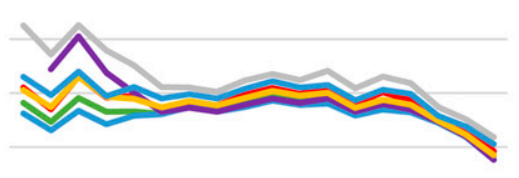

1234456789101112131415161718 WAT
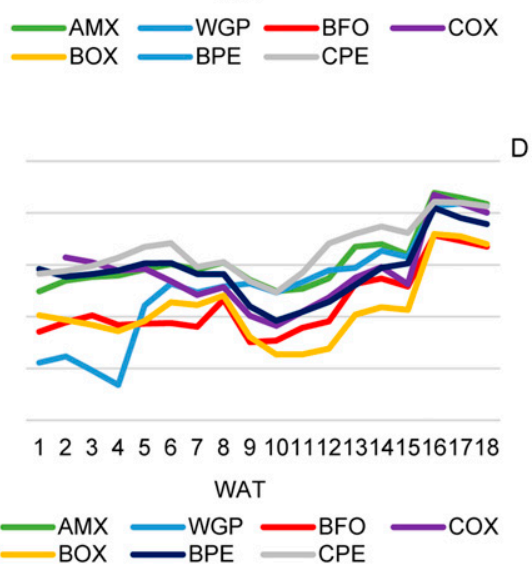

Fig. 2. Weekly soil temperature $\left({ }^{\circ} \mathrm{C}\right)$ and moisture $\left(\mathrm{m}^{3} \mathrm{~m}^{-3}\right)$ in 2018 (A and $\mathbf{C}$, respectively) and 2019 (B and D, respectively) under clear and black polyethylene mulch (CPE and BPE) and soil-biodegradable mulch treatments [AMX-01 (AMX), WeedGuardPlus (WGP), Black Film Organic (BFO), Clear Organix $(\mathrm{COX})$, and Black Organix $(\mathrm{BOX})]$ recorded at 15 -min intervals for 16 weeks after transplanting (WAT) in 2018 (31 May to 17 Sept.) and 18 WAT (1 June to 2 Oct.) in 2019 at 10-cm depth in the center of each plot in replicate 2. In 2018, the sensors in COX and AMX plots malfunctioned the first week and the last 2 weeks of the experiment, respectively. BOX was not included in 2018.

respectively). In 2018, the average number of wipes to remove adhered mulch was highest for BFO (1.9 wipes), which was similar to COX (1.1 wipes); was intermediate for WGP (1.0 wipe); and was lowest for AMX, BPE, and CPE ( 0 wipes on average) $(P=0.03$; Table 4). In 2019, the average number of wipes to remove adhered mulch was highest for WGP (2.2 wipes); intermediate for AMX, COX, BOX, and BFO (1.3 wipes on average); and was lowest for BPE and CPE (0 wipes on average $)(P<0.0001)$.

In 2019, mulch adhesion removal postharvest differed due to treatment $(P=0.006)$ and time after harvest $(P<0.0001 ;$ Tables 4 and 5). More wipes were needed to remove adhered BOX, WGP, and COX (3.9 wipes on average), and fewer wipes were needed for AMX (2.7 wipes) (Table 4). Removal of adhered BFO (5.9 wipes) did not differ statistically from other treatments because of the high variation among plots for this treatment (no sampled fruit had mulch adhesion at 1, 4, and $24 \mathrm{~h}$ postharvest). Overall, the number of wipes to remove adhered mulch was lowest at harvest $(0 \mathrm{~h})$ and $24 \mathrm{~h}$ postharvest $(1.5$ wipes on average), which were similar to $1 \mathrm{~h}$ postharvest (2.9 wipes), whereas the greatest number of wipes for removal of adhered mulch occurred at $2,2.5$, and $4 \mathrm{~h}$ postharvest (5.5 wipes on average) $(P<0.0001$; Table 5$)$. The number of wipes for mulch adhesion removal increased from 1.8 wipes at harvest to 6.8 wipes $2.5 \mathrm{~h}$ after harvest. Moisture on the fruit surface did not differ due to treatment $(P=0.12)$, but did differ due to time after harvest $(P<0.0001$; Table 5$)$. Moisture on the fruit surface was $0.0023 \mathrm{~g} / \mathrm{cm}^{2}$ at harvest and decreased steadily over time, and was $0 \mathrm{~g} / \mathrm{cm}^{2}$ at $4 \mathrm{~h}$ postharvest $(P<$ 0.0001 ). At $24 \mathrm{~h}$ postharvest, moisture on the fruit surface was similar to time of harvest $\left(0.0031 \mathrm{~g} / \mathrm{cm}^{2}\right)$. There was a significant correlation between moisture on the fruit surface and number of wipes for removal of adhered mulch $\left(R^{2}=0.31, P<0.0001\right)$, that is, as moisture on the fruit surface decreased, more wipes were needed to remove adhered mulch.

\section{Discussion}

All mulch treatments in this study except COX and CPE suppressed weeds, and only weeds in COX treatment grew significantly. Weeds germinated under all other mulch treatments but died soon after both years. Weed growth occurred beneath the clear plastic mulch treatments because they allowed light transmission (Cowan et al., 2014; Ghimire et al., 2020; Waterer, 2010; Wortman et al., 2016). However, weeds only continued to grow in COX due to splitting early in the season, similar to results of Ghimire et al. (2020). The higher weed number for CPE in 2019 was likely due to higher soil moisture than in 2018, which provided a more conducive growing environment. Although there were several weeds found in WGP treatments in late season 2019 , they were only found in two plots where the mulches had deteriorated. Brault et al. (2002), Cowan et al. (2014), Ghimire et al. (2018, 2020), and Wortman et al. (2016) reported that BDMs controlled weeds and no weeds penetrated through BDMs, which was consistent with this study.

The higher PSE for BFO on 15 June 2018 was due to bird damage. Crows perched on the mulch in the BFO plots to feed on vertebrate animals, and this behavior was also observed in PE-covered raspberry beds by a grower in this region (Randy Hancoop, personal communication). In both years, increased PSE for all BDMs after 1 Aug. was 
Table 3. Total mean fruit number and weight $(\mathrm{kg})$, and mean fruit number and weight with mulch adhesion of 'Cinnamon Girl' pie pumpkin grown with polyethylene (CPE and BPE) and soil-biodegradable mulch treatments [AMX-01 (AMX), WeedGuardPlus (WGP), Black Film Organic (BFO), Clear Organix (COX), and Black Organix (BOX)] in 2018 and 2019; data are from 4 plants per plot.

\begin{tabular}{|c|c|c|c|c|c|c|c|}
\hline \multirow{2}{*}{ Treatment } & \multicolumn{3}{|c|}{ Fruit number } & \multicolumn{4}{|c|}{ Fruit wt (kg) } \\
\hline & Total $^{\mathrm{z}}$ & \multicolumn{2}{|c|}{ With mulch adhesion } & \multicolumn{2}{|c|}{ Total } & \multicolumn{2}{|c|}{ With mulch adhesion $(\mathrm{kg})$} \\
\hline$\overline{\mathrm{AMX}}$ & $16.3 \mathrm{ab}^{\mathrm{y}}$ & $0.0 \mathrm{c}$ & $4.0 \mathrm{c}$ & $20.2 \mathrm{~b}$ & 19.7 & $0.0 \mathrm{c}$ & $5.5 \mathrm{bc}$ \\
\hline $\mathrm{BFO}$ & $18.4 \mathrm{ab}$ & $8.8 \mathrm{a}$ & $3.0 \mathrm{c}$ & $26.3 \mathrm{a}$ & 20.0 & $13.5 \mathrm{a}$ & $3.7 \mathrm{c}$ \\
\hline $\mathrm{COX}$ & $16.0 \mathrm{ab}$ & $2.0 \mathrm{~b}$ & $4.8 \mathrm{bc}$ & $20.5 \mathrm{~b}$ & 20.7 & $3.0 \mathrm{~b}$ & $5.6 \mathrm{bc}$ \\
\hline $\mathrm{BOX}^{\mathrm{x}}$ & $18.8 \mathrm{a}$ & - & $10.3 \mathrm{a}$ & - & 22.4 & - & $11.8 \mathrm{a}$ \\
\hline BPE & $19.0 \mathrm{a}$ & $0.0 \mathrm{c}$ & $0.0 \mathrm{~d}$ & $27.1 \mathrm{a}$ & 23.7 & $0.0 \mathrm{c}$ & $0.0 \mathrm{~d}$ \\
\hline
\end{tabular}

${ }^{\mathrm{z}}$ Data are combined for 2018 and 2019 because there was no statistical difference due to year nor was there an interaction between year and treatment.

${ }^{\mathrm{y}}$ Means followed by the same letter in the same column are not significantly different at $P<0.05$. All data were analyzed with analysis of variance, and means separation were done with Tukey honest significance test, except fruit number and yield with mulch adhesion were analyzed using a Wilcoxon nonparametric test and means separation were performed with a Wilcoxon nonparametric multiple comparison.

${ }^{\mathrm{x}}$ This treatment was not included in 2018.

Table 4. Mean number of wipes at harvest needed to remove adhered mulch from 'Cinnamon Girl' pie pumpkin fruit grown with polyethylene (CPE and BPE) and soil-biodegradable mulch treatments [AMX-01 (AMX), WeedGuardPlus (WGP), Black Film Organic (BFO), Clear Organix (COX), and Black Organix (BOX)] at harvest in 2018 and 2019 and postharvest in 2019.

\begin{tabular}{lccc}
\hline & \multicolumn{2}{c}{ No. wipes at harvest } & \\
\cline { 2 - 3 } Treatment & 2018 & 2019 & No. wipes postharvest $^{2}$ \\
AMX & $0.0 \mathrm{c}^{\mathrm{y}}$ & $1.4 \mathrm{~b}$ & 2019 \\
WGP & $1.0 \mathrm{~b}$ & $2.2 \mathrm{a}$ & $2.7 \mathrm{~b}$ \\
BFO & $1.9 \mathrm{a}$ & $1.2 \mathrm{~b}$ & $3.9 \mathrm{a}$ \\
COX & $1.1 \mathrm{ab}$ & $1.3 \mathrm{~b}$ & $5.9 \mathrm{abc}^{\mathrm{x}}$ \\
BOX & $-\bar{w}^{\mathrm{w}}$ & $1.3 \mathrm{~b}$ & $3.1 \mathrm{ab}$ \\
BPE & $0.0 \mathrm{c}$ & $0.0 \mathrm{c}$ & $4.6 \mathrm{a}$ \\
CPE & $0.0 \mathrm{c}$ & $0.0 \mathrm{c}$ & $0 \mathrm{c}$ \\
$P$ value & 0.03 & $<0.0001$ & $-\overline{0}$ \\
\hline
\end{tabular}

${ }^{2}$ Data combined for seven time points (hour:minute) postharvest $(0: 00,1: 00,1: 30,2: 00,2: 30,4: 00$, and 24:00).

${ }^{\mathrm{y}}$ Means followed by the same letter in the same column are not significantly different at $P<0.05$. All data were analyzed using a Wilcoxon nonparametric test and means separation were performed with a Wilcoxon nonparametric multiple comparison.

${ }^{\mathrm{x}} \mathrm{BFO}$ did not differ statistically from other treatments due to high variation and lack of fruit with mulch adhesion.

${ }^{\mathrm{w}} \mathrm{BOX}$ treatment was not included in 2018 and number of wipes postharvest was not measured for CPE in 2019.

Table 5. Mean number of wipes needed to remove adhered mulch from 'Cinnamon Girl' pie pumpkin fruit, and moisture $\left(\mathrm{g} / \mathrm{cm}^{2}\right)$ on the fruit surface just above adhered mulch in 2019. Fruits were wiped at the time of harvest $(0 \mathrm{~h})$ on 1 Oct. 2019 and six times after harvest ( 1 to $24 \mathrm{~h}$ ). Means are combined for all mulch treatments, except for the clear polyethylene mulch because only black polyethylene mulch was used as control.

\begin{tabular}{lcc}
\hline Treatment & No. wipes & Fruit surface moisture $\left(\mathrm{g} / \mathrm{cm}^{2}\right)$ \\
\hline $0 \mathrm{~h}$ & $1.8 \mathrm{c}^{2}$ & $0.0023 \mathrm{~b}$ \\
$1 \mathrm{~h}$ & $2.9 \mathrm{bc}$ & $0.0008 \mathrm{c}$ \\
$1.5 \mathrm{~h}$ & $4.5 \mathrm{ab}$ & $0.0001 \mathrm{~d}$ \\
$2 \mathrm{~h}$ & $4.1 \mathrm{a}$ & $0.0001 \mathrm{~d}$ \\
$2.5 \mathrm{~h}$ & $6.8 \mathrm{a}$ & $0.0000 \mathrm{~d}$ \\
$4 \mathrm{~h}$ & $5.4 \mathrm{a}$ & $0.0000 \mathrm{~d}$ \\
$24 \mathrm{~h}$ & $1.1 \mathrm{c}$ & $0.0031 \mathrm{a}$ \\
$P$ value & $<0.0001$ & $<0.0001$ \\
\hline
\end{tabular}

${ }^{\mathrm{z}}$ Means followed by the same letter in the same column are not significantly different at $P<0.05$. All data were analyzed using a Wilcoxon nonparametric test and means separation were performed with a Wilcoxon nonparametric multiple comparison.

mainly due to deterioration of the mulch under the fruit. The two paper mulches (WGP and AMX) performed differently each year, likely due to higher precipitation in $2019(212 \mathrm{~mm})$ than $2018(44 \mathrm{~mm})$ (WSU AgWeatherNet, 2019) that accelerated degradation (Brodhagen et al., 2015).

Plastic mulch treatments usually had higher soil temperature and volumetric water
2019). Higher permeability of soilbiodegradable plastic mulches allows water to evaporate through the mulch, which likely reduces both soil temperature and volumetric water content for BDMs compared with $\mathrm{PE}$ mulch as water evaporation is an endothermic process (Touchaleaume et al., 2016; Zhang et al., 2019, 2020). In addition, the difference in thickness of PE $(25.4 \mu \mathrm{m})$ and soil-biodegradable plastic mulches (15.2 to $17.8 \mu \mathrm{m})$ in this study could also contribute to the observed difference in soil temperature and moisture as thicker mulch retains moisture and reduces temperature (Zhang et al., 2019, 2020). The lower soil temperature for WGP (pinkish-brown in color) than AMX (black in color) was likely due to the mulch color as darker colors can absorb more solar energy than lighter colors (Lamont, 2005; Synnefa et al., 2007).

In general, total fruit number was higher under plastic mulch treatments compared with paper mulch treatments, which has also been observed for tomato (Solanum lycopersicum) (Miles et al., 2012). In the current study, plastic mulch treatments promoted pumpkin reproductive growth, likely due to higher soil temperature and volumetric water content compared with paper mulch treatments, which is consistent with Splawski et al. (2014). CPE had statistically similar yield to the two paper mulch treatments (AMX and WGP) due to the high variation within CPE plots (range was 23 to $28 \mathrm{~kg}$ ). There was no yield difference among treatments in 2019, likely because high precipitation led to significant infection by Pseudomonas syringae (Tymon et al., unpublished data) and subsequent fruit rot that similarly affected all plots.

Mulch adhesion occurred on fruit grown with all BDMs in this study except for AMX in 2018. Similarly, Ghimire et al. (2018) found that BDM adhered to pumpkin fruit, and Limpus et al. (2019) found that Mater-Bi plastic mulch adhered to the bottom of melon and pepper fruit as they matured. The number of fruit with mulch adhesion was higher in 2019 than 2018, likely due to higher precipitation in 2019 that could have accelerated 
the mulch deterioration process (Brodhagen et al., 2015). Particularly for WGP, a higher PSE was recorded in 2019 than 2018, and this coincides with increased mulch adhesion on fruit grown with WGP in 2019. In contrast, BFO had fewer fruit with mulch adhesion in 2019 than 2018. BFO was supplied separately each year for this experiment, and mulch may have had different physiochemical properties each year, resulting in the inconsistent deterioration between years (Hayes et al., 2012). COX had relatively fewer fruit with mulch adhesion compared with other soil-biodegradable mulches because many fruit in this treatment did not rest on the mulch as the mulch split early in the season. Adhesion of mulch to heavy fruit like pumpkin or watermelon occurs due to several mechanisms. BDMs have less cross-linking of polymer chains and can be broken up into smaller units through hydrolysis and the pressure of the fruit resting on the mulch (Hayes et al., 2012; Limpus et al., 2019). Stronger van der Waals adhesion is expected from BDMs due to their higher surface energy (Ha and Gardella, 2005), and water on the mulch surface promotes mulch degradation (Brodhagen et al., 2015), further enhancing diffusive adhesion of BDMs. Further, when water on BDM and fruit surfaces evaporates, capillary forces bring plastic and fruit surfaces closer together (Flury and Aramrak, 2017).

Ghimire et al. (2018) noticed that when pumpkin fruit with mulch adhesion were harvested and kept in a bin for several hours and then wiped, it was more difficult to remove adhered mulch from the fruit because the mulch dried on the fruit. In the current study, adhered mulch was easy to remove when fruit were wiped at harvest because the fruit surface was moist regardless of the time of day that fruit were harvested. The experimental site had high $\mathrm{RH}(\approx 90 \%)$ from midnight to midmorning (1000 HR) (WSU AgWeatherNet, 2019), resulting in water condensing on the fruit surface in the field and in storage in the open-ended high tunnel that was adjacent to the field site. However, in a drier climate than northwest Washington, adhered mulch likely will be more difficult to remove at harvest. In the current study for example, as the fruit surface dried postharvest, it became more difficult to remove adhered mulch.

\section{Conclusions}

Overall, all mulch treatments in this study provided adequate weed control except COX, and fruit yield (fruit number and weight) was generally higher for plants grown with plastic mulch compared with paper mulch treatments. Yield of pumpkin grown with black plastic BDM was similar to yield with black PE mulch, indicating black BDM can be a suitable alternative to black PE mulch. However, pumpkin yield with clear BDM was slightly lower than with clear PE mulch, likely due to early deterioration of the clear BDM. Pumpkin yield with black paper mulch was equal to brown paper mulch, suggesting paper color does not influence soil temperature. To our knowledge, this is the first study to assess hand-removal of adhered mulch from fruit and to explore the relationship between moisture on the fruit surface and mulch adhesion. Adhered mulch should be removed from the crop before fresh marketing or processing, thus, mulch adhesion results in added harvest time and labor. This study demonstrated that mulch adhesion can occur for all BDMs used in this experiment, and adhered mulch can easily be removed from fruit at harvest, regardless of harvest time as long as there is moisture on the fruit surface. However, the number of wipes to remove adhered mulch differed due to mulch treatment and time postharvest as the fruit surface dried. Growers need to consider the costs of removing BDM from fruit before marketing.

\section{Literature Cited}

Al-Assir, I.A., I.G. Rubeiz, and R.Y. Khoury. 1992. Yield response of greenhouse cantaloupe to clear and black plastic mulches. Biol. Agr. Hort. 8(3):205-209.

Anderson, D.F., M.A. Garisto, J.C. Bourrut, M.W Schonbeck, R. Jaye, A. Wurzberger, and R. DeGregorio. 1996. Evaluation of a paper mulch made from recycled materials as an alternative to plastic film mulch for vegetables. J. Sustain. Agr. 7(1):39-61.

Brault, D., K.A. Stewart, and S. Jenni. 2002. Growth, development, and yield of head lettuce cultivated on paper and polyethylene mulch. HortScience 37:92-94.

Briassoulis, D. 2006. Mechanical behavior of biodegradable agricultural films under real field conditions. Polym. Degrad. Stabil. 91:1256-1272.

Brodhagen, M., M. Peyron, C. Miles, and D.A. Inglis. 2015. Biodegradable plastic agricultural mulches and key features of microbial degradation. Appl. Microbiol. Biotechnol. 99:10391056.

Cowan, J.S., C.A. Miles, P.K. Andrews, and D.A. Inglis. 2014. Biodegradable mulch performed comparably to polyethylene in high tunnel tomato (Solanum lycopersicum L.) production. J. Sci. Food Agr. 94:1854-1864.

Dabirian, S., D.A. Inglis, and C.A. Miles. 2017. Grafting watermelon and using plastic mulch to control verticillium wilt caused by Verticillium dahliae in Washington. HortScience 52:349356.

DeVetter, L.W., H. Zhang, S. Ghimire, S. Watkinson, and C.A. Miles. 2017. Plastic biodegradable mulches reduce weeds and promote crop growth in day-neutral strawberry in western Washington. HortScience 52:1700-1706.

European Norms (EN) 17033. 2018. PlasticsBiodegradable mulch films for use in agriculture and horticulture: Requirements and test methods. European Standard, European Committee for Standardization, Brussels, Belgium.

Flury, M. and S. Aramrak. 2017. Role of air-water interfaces in colloid transport in porous media: A review. Water Resour. Res. 53(7):5247-5275.

Ghimire, S., A.L. Wszelaki, J.C. Moore, D.A. Inglis, and C. Miles. 2018. The use of biodegradable mulches in pie pumpkin crop production in two diverse climates. HortScience 53:288-294.
Ghimire, S., E. Scheenstra, and C.A. Miles. 2020. Soil-biodegradable mulches for growth, yield, and quality of sweet corn in a Mediterraneantype climate. HortScience 55:317-325.

Goldberger, J.R., R.E. Jones, C.A. Miles, R.W. Wallace, and D.A. Inglis. 2015. Barriers and bridges to the adoption of biodegradable plastic mulches for US specialty crop production. Renew. Agr. Food Syst. 30:143-153.

Ha, C.S. and J.A. Gardella. 2005. Surface chemistry of biodegradable polymers for drug delivery systems. Chem. Rev. 105(11):4205-4232.

Hayes, D.G. and M. Flury. 2018. Summary and assessment of EN 17033:2018, a new standard for biodegradable plastic mulch films. Report No. EXT-2018-012018. Mar. 2020. <https:// ag.tennessee.edu/biodegradablemulch/Documents/ EU\%20regs\%20factsheet.pdf $>$.

Hayes, D.G., S. Dharmalingam, L.C. Wadsworth, K.K. Leonas, C. Miles, and D.A. Inglis. 2012. Biodegradable agriculture mulches derived from biopolymers. Princ. Pract. 1114:201-222.

Kasirajan, S. and M. Ngouajio. 2012. Polyethylene and biodegradable mulches for agricultural applications: A review. Agron. Sustain. Dev. 32:501-529.

Lamont, W. 2005. Plastics: Modifying the microclimate for the production of vegetable crops. HortTechnology 15:477-481.

Limpus, S., S. Heisswolf, D. Kreymborg, R. Wright, W. Hall, and S. Guerrini. 2019. Comparison of biodegradable mulch products to polyethylene in irrigated vegetable, tomato and melon crops. Final report MT09068. Queensland Dept. Agr. Fisheries For., Queensland, Australia. Dec. 2019. <https://ausveg.com.au/app/data/technicalinsights/docs/130007_MT09068\%20Final\% 20Report\%20Complete.pdf>.

Liu, E.K., W.Q. He, and C.R. Yan. 2014. 'White revolution' to 'white pollution'-Agricultural plastic film mulch in China. Environ. Res. Lett. 9:091001.

MarketsandMarkets. 2017. Agricultural films market by applications and polymers-Global trends and forecasts to 2022. MarketsandMarkets Research Private Ltd., Maharashtra, India.

Martin-Closas, L., J. Costa, and A.M. Pelacho. 2017. Agronomic effects of biodegradable films on crop and field environment, p. 67104. In: M. Malinconico (ed.). Soil degradable bioplastics for a sustainable modern agriculture. Green Chem. Sustainable. Technol. Springer, Germany.

Miles, C., R. Wallace, A. Wszelaki, J. Martin, J. Cowan, T. Walters, and D. Inglis. 2012. Deterioration of potentially biodegradable alternatives to black plastic mulch in three tomato production regions. HortScience 47:12701277.

Oregon State University. 2019. Oregon Vegetables: Squash, pumpkin, and winter. June 2019. $<$ https://horticulture.oregonstate.edu/oregonvegetables/squash-pumpkin-and-winter>.

Peel, M.C., B.L. Finlayson, and T.A. McMahon. 2007. Updated world map of the KöppenGeiger climate classification. Hydrol. Earth Syst. Sci. 11:1633-1644.

Sintim, H.Y., S. Bandopadhyay, M.E. English, A.I. Bary, J.M. DeBruyn, S.M. Schaeffer, C.A. Miles, J.P. Reganold, and M. Flury. 2019. Impacts of biodegradable plastic mulches on soil health. Agr. Ecosyst. Environ. 273:36-49.

Splawski, C.E., E.E. Regnier, S.K. Harrison, K. Goodell, M.A. Bennett, and J.D. Metzger. 2014. Mulch effects on floral resources and fruit production of squash, and on pollination and nesting by squash bees. HortTechnology 24:535-545. 
Synnefa, A., M. Santamouris, and K. Apostolakis. 2007. On the development, optical properties and thermal performance of cool colored coatings for the urban environment. Sol. Energy 81(4):488-497.

Touchaleaume, F., L. Martin-Closas, H. AngellierCoussy, A. Chevillard, G. Cesar, N. Gontard, and E. Gastaldi. 2016. Performance and environmental impact of biodegradable polymers as agricultural mulching films. Chemosphere 144: 433-439.

U.S. Department of Agriculture (USDA). 2019. Web soil survey. Sept. 2019. < https://websoilsurvey. sc.egov.usda.gov>.
Washington State University (WSU) AgWeatherNet. 2019. Washington State Univ. AgWeatherNet, Mount Vernon, WA. Sept. 2019. $<$ http://weather.wsu.edu/ $>$.

Waterer, D. 2000. Effect of soil mulches and herbicides on production economics of warm season vegetable crops in a cool climate. Hort Technology 10:154-159.

Waterer, D. 2010. Evaluation of biodegradable mulches for production of warm-season vegetable crops. Can. J. Plant Sci. 90(5):737743.

Wortman, S.E., I. Kadoma, and M.D. Crandall. 2016. Biodegradable plastic and fabric mulch performance in field and high tunnel cucumber production. HortTechnology 26:148-155.

Zhang, H., C. Miles, S. Ghimire, C. Benedict, I. Zasada, and L. DeVetter. 2019. Polyethylene and biodegradable plastic mulches improve growth, yield, and weed management in floricane red raspberry. Scientia Hort. 250:371379.

Zhang, H., C. Miles, S. Ghimire, C. Benedict, I. Zasada, H. Liu, and L.W. DeVetter. 2020. Plastic mulches improved plant growth and suppressed weeds in late summer-planted floricane-fruiting raspberry. HortScience 55:565-572. 